\title{
Combined Spinal Epidural versus Epidural Sufentanil and Bupivacaine in Labour (Clinical and Histological comparative Study)
}

\author{
*Nagia M. Abd El Moeti, *Zinab B. Youssef, *Soaad S. Abd El Aal \\ **Mahmoud Ahmed Abd El Haliem \\ *Anaesthesia department Faculty of medicine Al-Azhar university \\ ** Histology department Faculty of Medicine Al Azhar university
}

\begin{abstract}
Introduction:- Regional analgesia provides excellent pain relif in labour. This study was designed to compare combined spinal eqidural (CSE) versus epidural block using a narcotic (sufentanil) and local anaesthetic bupivacaine regarding their effects on progress of labour, method of delivery, pain relif, side effects and neonatal outcome.

Patients and Methods :-Forty pregnant women ASA I and II were enrolled in this study. The women were randomly allocated to receive either CSE or epidural ( 20 patient of each ). In CSE group analgesia was initiated with $10 \mathrm{ug}$ sufentanil with $2 \mathrm{mg}$ bupivacaine. In epidural group $10 \mathrm{ml}$ bupivacaine $0.125 \%$.and $10 \mathrm{ug}$ sufentanil injected epidurally. In both groups the continuous infusion of $0.83 \%$ bupivacaine with $0.33 \mathrm{ug} / \mathrm{ml}$ sufentanil at $10 \mathrm{ml} / \mathrm{hr}$ adjusted as required. Maternal haemodynamics, analgesia characteristics VAPS, degree of motor block, were measured. Duration of labour, cervical dilation, maternal satisfaction and mode of delivery were assessed. Foetal outcome was assessed by 1 and $5 \mathrm{~min}$. Apgar score and umbilical venous blood gases. Maternal and neonatal side effects were observed.

The experimental study was done on 30 rats divided into 3 groups 10 rats of each. Control group (A) injected intrathecally with saline, group (B) injected intrathecally with $1.5 \mathrm{ug} / \mathrm{kg}$ sufentanil (low dose), and group (C) injected intrathecally with $7.5 \mathrm{ug} / \mathrm{kg}$ sufentanil (high dose), the pervious doses were injected every $2 \mathrm{hr}$. for 3 times then the spinal cord was obtained and stained for histological evaluation.

Results:- The clinical study showed that no difference between the 2 groups for the degree of motor block or adequacy of analgesia, mode of delivery and Foetal outcome. The onset of analgesia was faster with CSE technique, more patient satisfaction and more pruritis.

The histological results revealed that no detectable significant neurotoxic changes with the use of small dose of intrathecal sufentanil but mild changes occurred with high dose.

Conclusion :- So the study concluded that both CSE and epidural analgesia with sufentanial and bupivaine can provide effective labour analgesia with minimal or no side effects.
\end{abstract}

\section{Introduction}

There has been considerable controversy in the past few years regarding the effect of epidural analgesia on the outcome of labour. Chestnut (1997). Labour epidural analgesia is associated with an increased incidence of cesarean deliveries for dystocia in nulliparous women and an increase in forceps deliveries in all parturients.

However, a more recent study, which compared epidural analgesia with intravenous patient - controlled analgesia during labour showed no difference in the incid- ence of cesarean deliveries between groups. Sharma et al. ( 1997 ).

Combined spinal epidural (CSE) analgesia with intrathecal sufentanil is a technique that offers the potential to minimize the effects of epidural analgesia during labour on the cesarean birth rate. This technique necessitates smaller doses of local anaesthetics which theoretically could reduce motor block.

The benefits of intrathecal sufentanil include rapid onset of pain relief and the 
ability to ambulate in early labour. Norris et al. (1994).

The administration of opioids epidurally and intrathecally for pain management is well established, a large number of opioids have been administered in the hope of providing segmental analgesia without serious adverse effects. The principal problem with the technique is the occurance of Late-onset respiratory depression. However, with few exceptions, there is a general lack of neurotoxicity data for most of the opioids that have been used in humans. Rawel et al. (1991).

The aim of this study is to compare between CSE versus epidural block using a narcotic (sufentanil) and local anaesthetic ( bupivacaine ) regarding their effects on the progress of labour, mode of delivery, pain relief satisfaction, side effects, foetal and neonatal outcome. Also, the effect of intrathecal sufentanil on spinal cord cells histologically.

\section{Patients and Methods}

Forty pregnant women ASA I and II physical status with single pregnancy in the vertex presentation were enrolled in this study. All patients were nulliparous and in active labour with regular uterine contractions and at least $3 \mathrm{~cm}$ cervical dilation. Parturients with pre-eclampsia, diabetes, preterm labour, bleeding problems or cervical dilattion $5 \mathrm{~cm}$ on admission were excluded.

The women were randomly allocated to receive either a combined spinal epidural (CSE group ), or epidural analgesia (epi group) in both groups CSE and epidural groups, intravenous access was secured and a preload of 500-1000 $\mathrm{ml}$ of ringer's solution was given.

\section{CSE group; Group I}

Women in the CSE group $(n=20)$ underwent combined spinal epidural analgesia. Following insertion of a $18 \mathrm{G}$ weiss Tuohy needle into the epidural space using loss of air resistance technique, a 27 gauge whitecare spinal needle was passed through the epidural needle into the subarachnoid space (combined spinal epidural miniset, portex). After clear cerebrospinal fluid was aspirated, analgesia was initiated with 10ug sufentanil $+2 \mathrm{mg}$ bupivacaine. Then the spinal needle was removed. An epidural catheter was advanced $3-5 \mathrm{~cm}$ in the epidural space and secured, test dose ( $45 \mathrm{mg}$ lidocaine and $15 \mu \mathrm{g}$ epinephrine ) was given.

\section{Epidural group (Epi group); Group II}

Women in the epi-group $(n=20)$ underwent epidural analgesia. The epidural space was located and a catheter was placed $3-5 \mathrm{~cm}$ in epidural space. After injection of

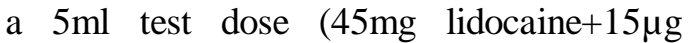
epinephrine), then $10 \mathrm{ml}$ bupivacaine $0.125 \%$ and 10ug sufentanil administered through the catheter.

In both groups, the regional anaesthetic technique was performed in the left lateral recumbent position. Back of the patients was sterilized with povidone iodine solution. Local infiltration with $2 \mathrm{ml}$ $1 \%$ lidocaine was given at the site of block. The epidural space was entered using a midline approach at the L2-3 or L3-4 interspace with an 18 gauge Weiss-Touhy needle using the loss of resistance to air technique. In both groups the continuous infusion of $0.083 \%$ plain bupivacaine with $0.33 \mathrm{ug} / \mathrm{ml}$ sufentanil at $10 \mathrm{ml} /$ hour adjusted as required within range of $8-12 \mathrm{ml} / \mathrm{h}$.

Maternal mean arterial blood pressure (MAP) and heart rate (HR) will be monitored every $10 \mathrm{~min}$. for the $1^{\text {st }} 30 \mathrm{~min}$ and then every hour till the end of delivery. The occurrence of hypotension ( defined as a decrease in mean blood pressure of more than $20 \%$ from baseline ), was treated with maternal oxygen administration, I.V. fluids or ephedrine (5-10mg). continuous arterial oxygen saturation using pulse oximetry.

Labour pain was assessed using a visual analogue scale (VAPS), on a scale of $0-10 \mathrm{~cm}(0=$ no pain and $10=$ worst possible pain ) was recorded immediately before analgesia, and at $5 \mathrm{~min}$ intervals for $1^{\text {st }} 30$ min then every hour until delivery. Motor blockade was assessed using a bromage scale $(1=$ complete motor block , $2=$ able to move feet only almost complete ), $3=$ 
just able to move knees ( partial ), 4 = full flexion of feet and knees ( none ). This was assessed $30 \mathrm{~min}$ after regional injection then every 1 hour till delivery. The level of sensory blockade ( to ice ) was assessed 5,15 and $30 \mathrm{~min}$ after regional analgesia. Also, the quality of pain relif during $1^{\text {st }}, 2^{\text {nd }}$ stage of labour and one day post partum was assessed using a 4 point scale (excellent, good, fair or poor ) patient satisfaction. Foetal heart rate ( FHR ) and uterine activity were monitored continuously for $30 \mathrm{~min}$ after commencing of analgesia then every $30 \mathrm{~min}$ in $1^{\text {st }}$ stage of labour and every $15 \mathrm{~min}$ in the $2^{\text {nd }}$ stage. The mode of delivery (spontaneous vaginal delivery, vacuum extraction, forceps delivery or caesarean section), and neonatal Apgar scores were recorded at one and 5 min. Foetal bradycardia $(<120$ b/pm) was treated with maternal oxygen, I.V. Fluids, ephedrine or terbutaline as indicated. Also, the duration of $1^{\text {st }}$ and $2^{\text {nd }}$ stages of labour, degree of cervical dilatation and foetat outcome was recorded

Maternal tympanic temperature was measured during the course of Labour using a genius thermometer (Sherwood medical, St. Louis, Mo). Intrapartum fever was defined as maternal temperature of $38.0^{\circ} \mathrm{C}$ or greater during the course of Labour. Neonates were evaluated for sepsis, which included a complete blood count and blood culture. At delivery, blood samples were collected from umbilical artery and vein for blood gases.

Side effects, such as nausea, vomiting, pruritus, headache, respiratory depression < $8 \mathrm{breath} / \mathrm{min}$. were recorded. Sedation was graded as $0=$ none, $1=$ easily arousable by light touch, 2=arousable with shaking, $3=$ arousable with painful stimuli and 4=unarousable.

\section{Histological Method :}

The study was done on 30 female albino rats divided into 3 groups.

\section{Group A ( 10 rats ) :}

Control group injected intrathecally with saline.

\section{Group B ( 10 rats ) :}

Injected intrathecally with low dose sufentanil $(1.5 \mathrm{ug} / \mathrm{kg})$.

\section{Group C ( 10 rats ) :}

Injected intrathecally with high dose sufentanil $(7.5 \mathrm{ug} / \mathrm{kg})$.

The previous doses were administered every $2 \mathrm{~h}$ for 3 times. The intrathecal injection was done after shaving the skin of the back, sterilization of the site of injection which is between $3^{\text {rd }}$ and $4^{\text {th }}$ lumbar vertebrae. In the $2^{\text {nd }}$ day of injection, the animal was fully anaesthetized by ether then scarified and dissected to obtain spinal cord and stained for histological evaluation. The spinal cord was fixed by :-

\section{- Neutral buffered formalin :}

Mainly used for specimens stained by haematoxylin and silver. The cord was immersed in the fixative up to 4 days followed by washing in running tap water, overnight, followed by dehydration and clearing in xylol.

\section{- Bouin Fluid :}

Mainly used for specimens stained by Toluidin blue, the fixation time was 2 days, followed by washing in 70\% alcohol followed by dehydration and clearing in xylol.

The specimens was embedded in hard grade of paraffin wax. Then section was done using rotator microtome at thickness of $6 \mathrm{~mm}$. Mounting was done on slides smeared with egg albumen. The sections were spread on a warming plate at a temperature of about $40 \mathrm{C}^{\circ}$, then they were kept for $2 \mathrm{~h}$ in an incubator at $37 \mathrm{C}^{\circ}$ to dry. Different staining methods were used to show different elements of the nerve cells and fibers in the spinal cord.

\section{I- Haematoxylin and Eosin :}

Was mainly used for staining the sections needed for demonstration of general structure of the nervous elements.

\section{Haematoxylin ( Erlich; s(HX) :-}

Haematoxylin $20 \mathrm{~g}$, Absolute alcohol $100 \mathrm{ml}$, Glycerine $100 \mathrm{ml}$, Distilled water $100 \mathrm{ml}$, Glacial acetic acid 10ml, Potash alum $10-40 \mathrm{~g}$.

\section{Eosine :}

[ Eosine $1.0 \mathrm{~g}$, distilled water $100 \mathrm{ml}$, Glacial acetic acid $0.5 \mathrm{ml}]$. Deparaffinize and bring section down to water, stain in Erlich; s HX for $5 \mathrm{~min}$. blue in tap water for 3 min. Stain in $1 \%$ an aqueous Esoine solution for $1 \mathrm{~min}$. Then wash in water and 
dehydrate in alcohol, clear in xylol and mount in Canada balsam.

$\frac{\text { II- Toluidine blue method ( Ralis et }}{\frac{\text { al.,1973) }}{\text { For detection of Nissle's granules. }}}$ Stain in $1 \%$ toluidine blue solution for 5 10 min., rinse in water, then dehydrate quickly and rinse in $70 \%$ alcohol. Clear in xylol and mount in Canada balsam.

III- Methyl green pyronin method
$\frac{\text { (Bancroft. Etal., 1975): }}{[2 \% \text { Methyl green } 7.2 \mathrm{ml}, \quad 2 \%}$
pyroniny $7.5 \mathrm{ml}, 0.1 \mathrm{~m}$ acetate buffer ph4.8 $2.5 \mathrm{ml}$, cloroform $30 \mathrm{ml}$.] stain in methyl green pyronin solution for $4-10 \mathrm{~min}$, blot dry, rinse rapidly in absolute acetone, then rinse in 10\% acetone in xylene.

IV silver method (Nauta and Gygax, 1951).

For demonstration the degenerating nerve fibers. The section was placed for $6 \mathrm{~h}$ in $[50 \%$ ethyl alcohol 100 parts and ammonium hydroxide 1 part], sections were washed in distilled water, then put in [silver nitrate $1.5 \% 95$ parts and white pridine 5 parts]. After that the sections was left in dark place for $24 \mathrm{~h}$, then put in $[20 \mathrm{ml}$ silver nitrate $4.5 \%$, pure ethyl alcohol $10 \mathrm{ml}$, ammonium hydroxide $1.8 \mathrm{ml}, 1.5 \mathrm{ml}$ sod. Hydroxide $2.5 \%$, equal parts of $1 \%$ citric acid and $10 \%$ formalin] the sections were dehydrated, clearing and mounting in Canada balsam.

\section{Statistical analysis :}

Data were presented as mean (SD). Statistical analysis were performed using Spss for windows V10 (Spss, Chicago IL, USA). Parametric data were compared using two sided; two sample T-tests and non-parametric data were compared using the Mann-Whithey $U$ test. Discrete data were compared by Chi-square. $\mathrm{P}$ value of $<0.05$ was considered statistically significant.

\section{Clinical Results :}

The groups did not differ regading demographic variables. Table (1).

There was highly significant difference in Bromage scale at 30min. between groups, CSE group had higher score. Then both groups showed no significant difference in Bromage scale at $1^{\text {st }}$ hour till the time of delivery, table (2).
The study showed faster onset time of analgesia in CSE group (5.5 \pm 3.72$) \mathrm{min}$. Compared to Epi group $(20.7 \pm 9.8) \mathrm{min}$. $(\mathrm{p}<0.001)$. but, there was no difference in upper sesory level $(\mathrm{T} 7 \pm 1.5)$ CSE and (T7 \pm 1$)$ Epi group. On the other hand CSE group showed high significant difference in VAPS $\varangle 3 \mathrm{~cm}$. at $5,10,15,20 \mathrm{~min}$. compared to Epi group ( $<<0.001)$, Thirty min. later and up to delivery time there was no difference in VAPS $<3 \mathrm{~cm}$. in both groups ( $\mathrm{p}<0.05)$.

The time from injection of initial analgesic dose to maternal request for additional analgesia was similar between both groups. But the epidural group had more analgesic solution requirements than CSE group [104.7(16.2)]ml versus [90.3(14.2)ml, table (3).

As regard to maternal satisfaction the study showed that CSE group was more satisfied at the time of complete analgesia than epidural group with significant difference while there was no significance difference between the 2 groups at time of delivery and one day postpartum [Table (4)].

There is no significant difference between CSE and epidural groups in initial cervical dilation, type of Labour, mode of delivery (normal, instrumental or C.S), duration of $2^{\text {nd }}$ stage of labour. But the CSE group showed significant decrease in the time from starting analgesia till full cervical dilation $(\mathrm{p}<0.05)$, the mean values of cervical dilation were $2.1 \pm 1.89 \mathrm{~cm} / \mathrm{hr}$ vs $1.3 \pm 0.71 \mathrm{~cm} / \mathrm{hr}$ in the CSE and epidural group respectively, table (5).

By comparing the MAP in both CSE and Epi groups, there were no significant difference in MAP (mean arterial blood pressure) at 5,10,15,30 min. and every hour till the time of delivery. The maternal MAP ranged from $86.6(2.5) \mathrm{mmHg}$ to 98.3 (3.2) $\mathrm{mmHg}$ in CSE and in Epi group it ranged from $85.4(2.5) \mathrm{mm} \mathrm{Hg}$ to 96.4 (2.7)mm Hg. The maternal HR ranged from 82 (11) to 97(12) b/min in CSE group and from 83(10) to 96(11) b/min in Epi group. There was slight non significant decrease in maternal MAP and HR (compared to base line value) in both groups. However only one patient in Epi group reported hypotension managed by I.V fluids and ephedrine. 
No significant difference between both groups at 1 and $5 \mathrm{~min}$ after delivery according to Apgar score. The umbilical vein blood gases showed no significant differences as regard $\mathrm{pH}, \mathrm{Po} 2, \mathrm{PCo} 2$ and base excess in both groups, table (6).

Also the foetal heart rate showed no difference between both groups, table (6).

The incidence of pruritus in CSE group was significally higher $(8 / 20,40 \%)$ than Epi group $(3 / 20,15 \%)$. The other adverse effects were mostly of mild to moderate intensity and almost equally disturbed between both groups. (Table 7).

Both CSE group and Epi group are associated with $15 \%$ maternal fever but not associated by neonatal sepsis indicated byve blood culture and there was no neonatal deaths in the study. Pain relif was associated with light sedation in $2(10 \%)$ patient in CSE group and 3 patients (15\%) in Epi group.

No patient in either group developed respiratory depression ( $<12$ breaths $/ \mathrm{min})$ or $\mathrm{spo}_{2} \prec 96 \%$ (Table 7)

Histological results : (Tables 8,9)

Low dose group showed non significant changes in $\mathrm{Hx}$ \& Eosin sections compared to control group (fig 1,2). Also toluidine blue stained section showed slight pale nissle material with mean optical density $(0.33 \pm 0.009)$ compared to control group $(0.32 \pm 0.012)$ these changes were non significant (fig 4,5). The methyl green pyronin section show no apparent changes in RNA and DNA contents of nerve cell in low dose group $(0.55 \pm 0.02)(0.73 \pm 0.08)$ compared to control group $(0.55 \pm 0.05)$ $(0.73 \pm 0.03)$ (Fig 7,8). Also the silver stained section of low dose group showed few shrunked, and some fragmentation in nerve fiber compared to control group (Fig 10,11)

On the other hand high dose group stained with Hx \& Eosin showed that nerve cells were smaller and shrunken, there was significant decrease in the mean diameter of cytoplasm (31.73 \pm 0.44$)$ and nucleus of the nerve cell $(10.87 \pm 0.59)$ compared to control group (33.96 \pm 0.33$)$ and $(12.10 \pm 0.40)$ Fig. $(1,3)$.

Also, the toludine blue stained sections showed that most cells appear pale with marked chromatolytic changes compared to control group. There was significant changes in the mean optical density of nissle's material in high dose group $(0.46 \pm 0.04)$ compared to control group $(0.32 \pm 0.01)$ (Fig 4,6). The methyl green pyronin stained sections showed no apparent changes in mean optical density value in DNA and RNA in both high dose and control group (Fig 7,9). In silver stained section there was significant shrunked and fragmentation of nerve cells compared to control group (fig 10,12).

Table (1) : Demograhic and base line maternal and Foetal haemodynamics

\begin{tabular}{|c|c|c|}
\hline & CSE group & Epi. Group \\
\hline Age $(\mathrm{yr})$ & $28.3(3.83)$ & $26.4(4.08)$ \\
\hline Weight $(\mathrm{kg})$ & $80.1(7.4)$ & $76.6(8.7)$ \\
\hline $\begin{array}{c}\text { Cervical dilation before } \\
\text { analgesia }(\mathrm{cm})\end{array}$ & $3 \pm 1$ & $3 \pm 1$ \\
\hline Maternal MBP (mm Hg) & $94.2(6.5)$ & $95.3(6.1)$ \\
\hline Maternal HR (bpm) & $84.5(13.1)$ & $82.6(12.8)$ \\
\hline Foetal HR (bpm) & $128.7(20.6)$ & $129.9(20.5)$ \\
\hline
\end{tabular}

Data presented as mean (SD) 
Table (2) : comparison between Epi. Group and CSE group in Bromage scale.

\begin{tabular}{|l|l|l|l|l|}
\hline Variable & CSE group & Epi group & T & P \\
\hline Bromage scale at 30min & $4(0)$ & $3.2(0.5)$ & 8.6 & $<0.001$ \\
$1 \mathrm{hr}$ & $4(0)$ & $3.9(0.2)$ & 1.4 & $>0.05$ \\
\hline
\end{tabular}

Table (3) : Onset and duration of initial analgesic dose and total analgesic solution.

\begin{tabular}{|l|l|l|l|l|}
\hline Variable & \multicolumn{1}{|c|}{ CSE. Group } & \multicolumn{1}{|c|}{ Epi. Group } & T & P \\
\hline Onset of analgesia & $5.5(3.72)$ & $20.7(9.8)$ & 4.97 & $<0.001$ \\
VAPS at 0 min. & $8.37(0.99)$ & $8.5(1.23)$ & 0.46 & $>0.05$ \\
5 min. & $2.47(1.39)$ & $6.12(1.31)$ & 13.42 & $>0.001$ \\
10min. & $2.23(1.23)$ & $5.73(1.1)$ & 12.81 & $>0.001$ \\
15min. & $0.20(1.20)$ & $3.5(0.43)$ & 13.93 & $>0.001$ \\
20min. & $0.12(0.89)$ & $1.452(0.12)$ & 6.76 & $>0.01$ \\
30min. & $0.13(0.34)$ & $1.10(0.1)$ & 1.98 & $>0.05$ \\
2 hrs. & $0.27(0.63)$ & $0.1(0.25)$ & 0.40 & $>0.05$ \\
At delivery & $87.4(23.7)$ & $85.45)$ & 1.42 & $>0.05$ \\
\hline $\begin{array}{l}\text { Duration of analgesia after initial dose } \\
\text { (min.) }\end{array}$ & $90.3(14.2)$ & $104.7(16.2)$ & 2.77 & $>0.01$ \\
\hline Total analgesic solution (ml) & CSE & 0.48 & $>0.05$ \\
\hline
\end{tabular}

VAPS $=$ Visual analogue pain scale. $\quad \mathrm{CSE}=$ Combined spinal epidural.

Epi $=$ epidural data are presented as mean (SD) epidural

Table (4) : Patient satisfaction of pain relif.

\begin{tabular}{|l|c|c|c|c|}
\hline Variable & CSE group & Epi group & T & P \\
\hline - Satisfaction at complete analgesia. & 4(0) excellent & $3.2(0.4)$ good & 2.69 & $<0.01$ \\
- At time of delivery. & & & \\
- One day post-partum. & 3.6(0.4) good & $3.6(0.4)$ good & 0.26 & $>0.05$ \\
& $3.4(0.51)$ good & $3.4(0.51)$ good & 0.14 & $>0.05$ \\
\hline
\end{tabular}

Results are presented as mean (SD). $\mathrm{p}<0.05$ significant.

Table (5) : Comparison between CSE and Epi groups in obstetric data and mode of delivery.

\begin{tabular}{|c|c|c|c|c|}
\hline Variable & CSE group & Epi group & $\mathrm{T}$ & $\mathrm{P}$ \\
\hline $\begin{array}{l}\text { Initial cervical dilation }(\mathrm{cm}) \\
\text { Mode of Labour }\end{array}$ & $3.5(1.3)$ & $3.6(1.4)$ & 0.26 & $>0.05$ \\
\hline - Normal & $14(70 \%)$ & $13(65 \%)$ & 1.07 & $>0.05$ \\
\hline - Instrumental & $3(15 \%)$ & $3(15 \%)$ & 0.38 & $>0.05$ \\
\hline - C.S & $3(15 \%)$ & $4(20 \%)$ & 0.76 & $>0.05$ \\
\hline $\begin{array}{l}\text { - Time from starting analgesia till full } \\
\text { cervical dilatation }(\mathrm{hr}) \text {. } \\
\text { - Time of } 1^{\text {st }} \text { stage }(\mathrm{hr})\end{array}$ & $4.73(1.28)$ & $6.07(1.34)$ & 2.97 & $<0.05$ \\
\hline - Time of $2^{\text {nd }}$ stage (min) & $\begin{array}{c}5.93(1.58) \\
45.03(10.89)\end{array}$ & $\begin{array}{r}7.97(1.69) \\
47.66(9.52)\end{array}$ & $\begin{array}{l}2.86 \\
1.55\end{array}$ & $\begin{array}{l}<0.05 \\
>0.05\end{array}$ \\
\hline
\end{tabular}


Table (6) : Analysis of umbilical vein blood gases.

\begin{tabular}{|l|c|c|c|c|}
\hline Variable & CSE group & Epi group & T & P \\
\hline $\mathrm{pH}$ & $7.33(0.92)$ & $7.28(1.73)$ & 1.43 & $>0.05$ \\
$\mathrm{po} 2(\mathrm{mmHg})$ & $44.38(8.9)$ & $47.23(8.6)$ & 1.23 & $>0.05$ \\
$\mathrm{pCo}(\mathrm{mmHg})$ & $41.5(5.37)$ & $37.5(6.18)$ & 1.72 & $>0.05$ \\
$\mathrm{ABE}(\mathrm{mmoL} / \mathrm{L})$ & $-4.7(2.24)$ & $-4.5(2.89)$ & 0.24 & $>0.05$ \\
Foetal heart rate variation & $124(20)-141(9)$ & $126(19)-139(11)$ & 1.38 & $>0.05$ \\
(FHS) & & & \\
\hline
\end{tabular}

Results are presented a mean (SD).

Table (7) : Adverse - effects of the two groups.

\begin{tabular}{|l|c|c|c|c|}
\hline Variable & CSE group & Epi group & $\mathrm{T}$ & $\mathrm{P}$ \\
\hline - Pruritus. & $8 / 20(40 \%)$ & $3 / 20(15 \%)$ & 4.59 & $<0.05$ \\
- Maternal fever. & $3 / 20(15 \%)$ & $3 / 20(15 \%)$ & 0.1 & $>0.05$ \\
- Nausea \& Vomiting & $2 / 20(10 \%)$ & $2 / 20(10 \%)$ & 0.96 & $>0.05$ \\
- Foetal Bradycardia & 0 & $1 / 20(5 \%)$ & 0.36 & $>0.05$ \\
- Hedache & $1 / 20(5 \%)$ & $1 / 20(5 \%)$ & 0.28 & $>0.05$ \\
- Sedation. & $2 / 20(10 \%)$ & $3 / 20(15 \%)$ & 0.42 & $>0.05$ \\
\hline
\end{tabular}

Table (8) : Mean cell diameter of nerve cell and diameter of nerve cell nucleus in different groups.

\begin{tabular}{|l|c|c|c|c|c|c|}
\hline & \multicolumn{2}{|c|}{ Control group } & \multicolumn{2}{c|}{ Low dose group } & \multicolumn{2}{c|}{ High dose group } \\
\hline & Diameter of N.C & $\begin{array}{c}\text { Diameter of } \\
\text { Nuc. }\end{array}$ & $\begin{array}{c}\text { Diameter of } \\
\text { N.C }\end{array}$ & $\begin{array}{c}\text { Diameter of } \\
\text { Nuc. }\end{array}$ & $\begin{array}{c}\text { Diameter of } \\
\text { N.C }\end{array}$ & $\begin{array}{c}\text { Diameter of } \\
\text { Nuc. }\end{array}$ \\
\hline Mean & $33.96(0.33)$ & $12.10(0.4)$ & $33.63(0.67)$ & $11.78(0.52)$ & $31.73(0.44)$ & $10.87(0.59)$ \\
\hline T-Test & & & 0.092 & 0.07 & 2.08 & 3.02 \\
\hline P-Value & & \multicolumn{2}{|c|}{$>0.05$} & $>0.05$ & $<0.05$ & $<0.05$ \\
\hline
\end{tabular}

N.C $=$ Never cell $\quad$ Nuc $=$ Nucles $\quad \mathrm{p}<0.05=$ significant

Table (9) : Optical density representing the Nissle material, RNA and DNA content of never cell in different groups.

\begin{tabular}{|l|c|c|c|c|c|c|c|c|c|}
\hline & \multicolumn{3}{|c|}{ Control group } & \multicolumn{3}{c|}{ Low dose group } & \multicolumn{4}{c|}{ High dose group } \\
\hline & O.D of & O.D & O.D & O.D of & O.D & O.D & O.D of & O.D & O.D \\
& N.M & RNA & DNA & N.M & RNA & DNA & N.M & RNA & DNA \\
\hline Mean & 0.32 & 0.55 & 0.73 & 0.33 & 0.55 & 0.73 & 0.46 & 0.55 & 0.73 \\
& $(0.012)$ & $(0.05)$ & $(0.03)$ & $(0.009)$ & $(0.02)$ & $(0.08)$ & $(0.04)$ & $(0.03)$ & $(0.05)$ \\
\hline T-Test & & & & 0.5 & 0.18 & 0.5 & 2.72 & 0.5 & 0.47 \\
\hline P-Value & & & & $>0.05$ & $>0.05$ & $>0.05$ & $<0.05$ & $>0.05$ & $>0.05$ \\
\hline
\end{tabular}

N.M $=$ Nissle material

$\mathrm{p}<0.05=$ significant

O.D = optical density 


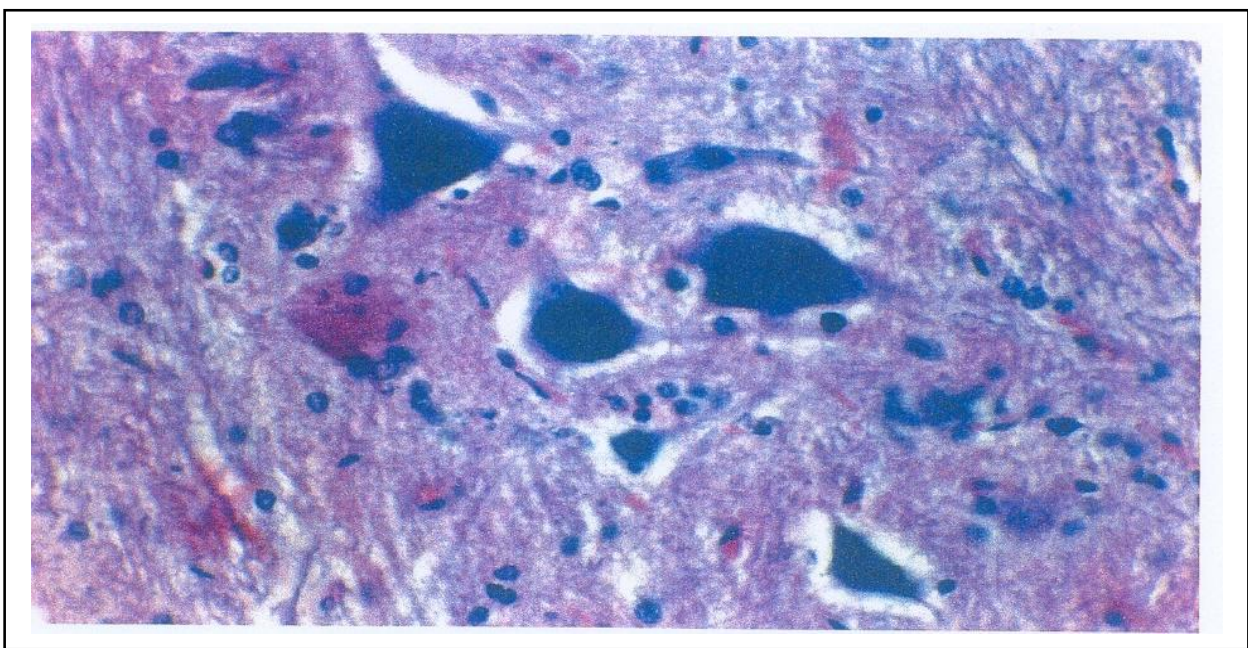

Fig (1) : Photomicrograph of section in rat's spinal cord showing the posterior horn cell of the control group (H\&E stain X500).

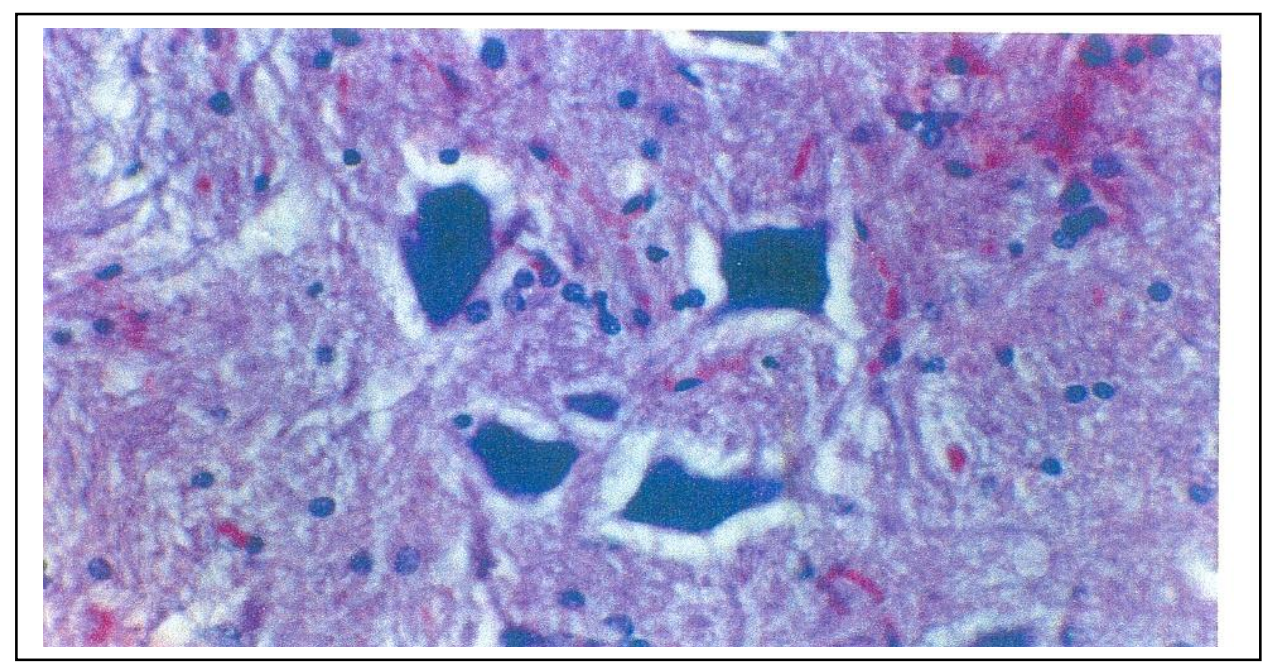

Fig (2) : Photomicrograph of section in rat's spinal cord showing the posterior horn cell after repeated intrathecal injection with low dose of sufentanil $(1.5 \mu \mathrm{g} / \mathrm{kg})$ group 11. showing various sizes types of nerve cells few cell appear smaller, most of them appear normal. (H\&E stain 500). 


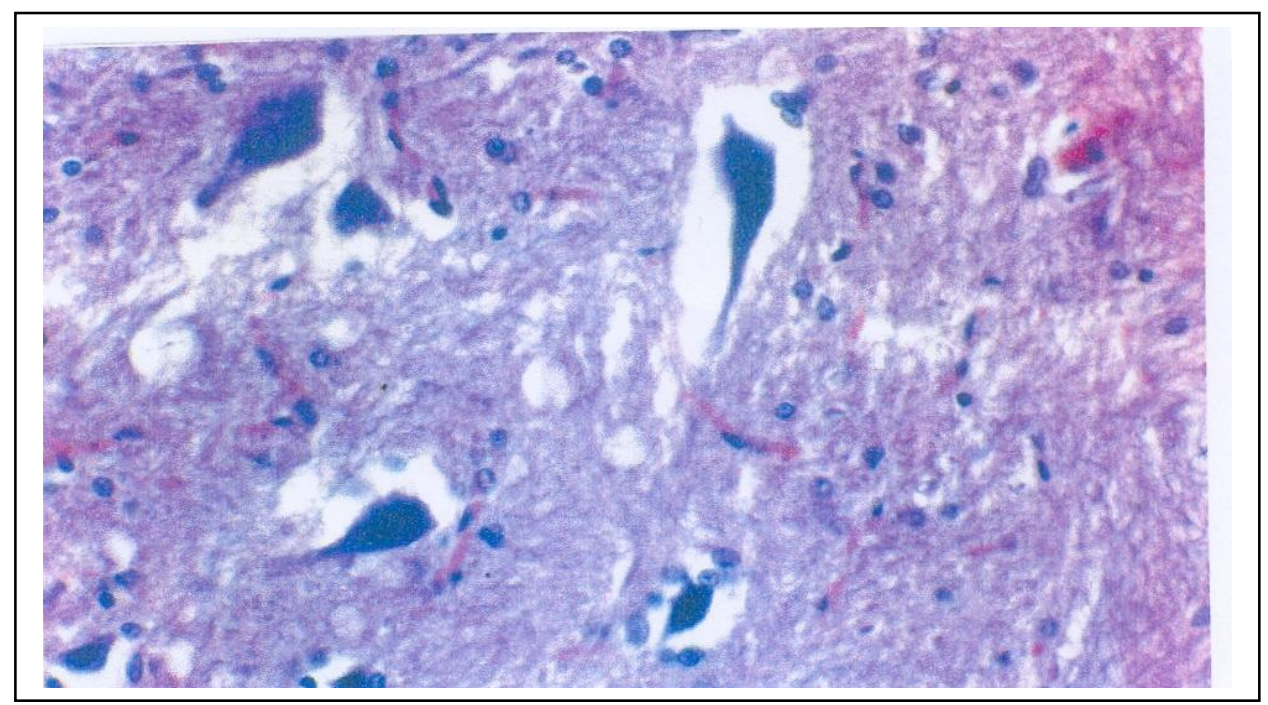

Fig (3) : Photomicrograph of section in rat's spinal cord showing the posterior horn cell after intrathecal injection with large dose of sufentanil $(7.5 \mu \mathrm{g} / \mathrm{kg})$ group 111. showing various sizes and types of nerve cells Most of cells appear smaller, few cells more or less normal (H\&E stain 500).

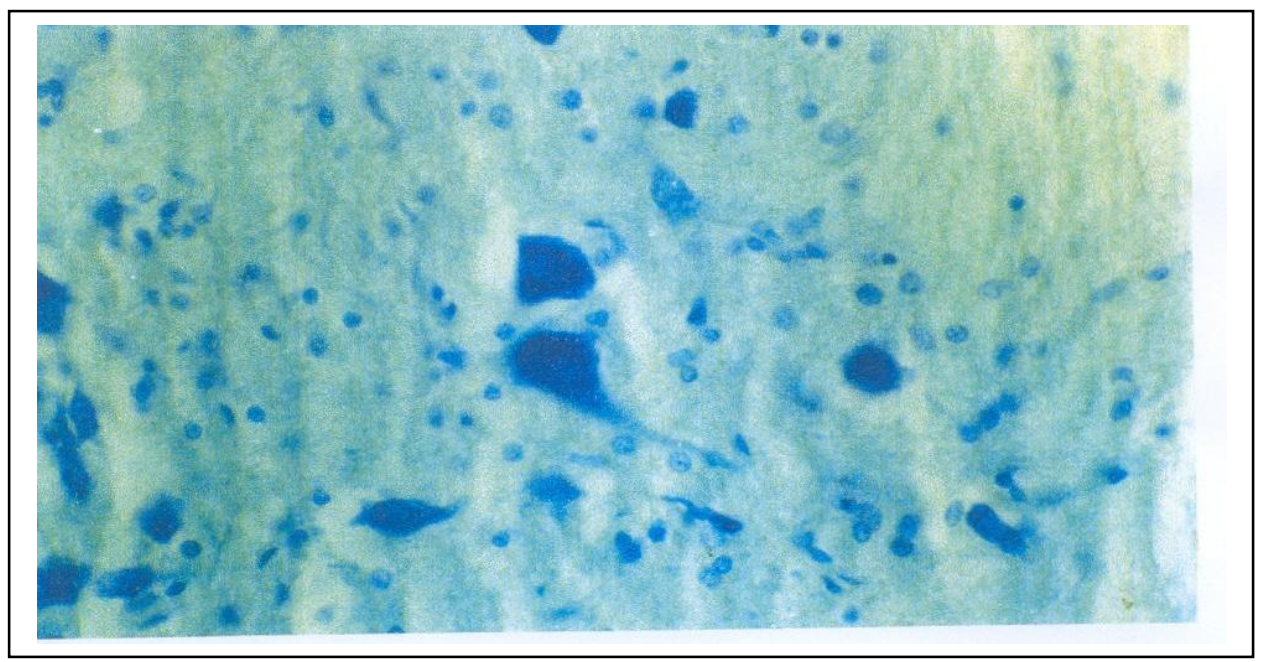

Fig (4) : Photomicrograph of section in rat's spinal cord showing the posterior horn cell of the control group showing the deeply stained nerve cells (Toluidine blue stain X500). 


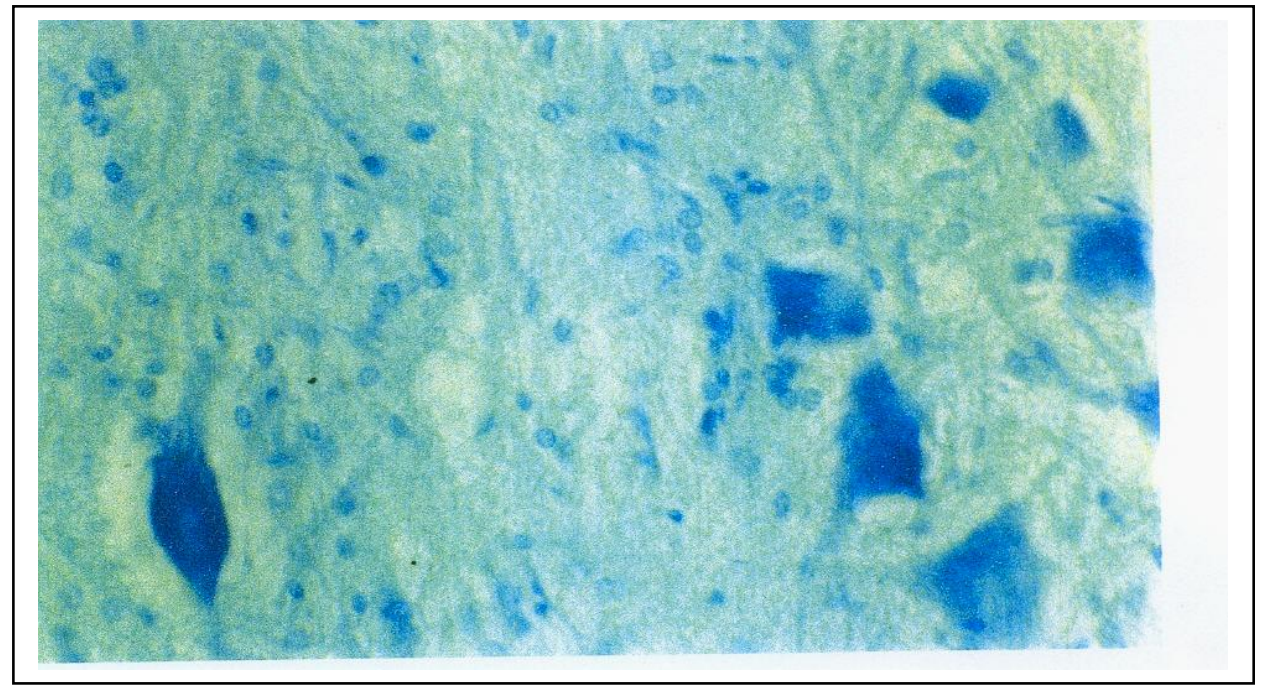

Fig (5) : Photomicrograph of section in rat's spinal cord showing the posterior horn cell after repeated intrathecal injection with low dose of sufentanil $(1.5 \mu \mathrm{g} / \mathrm{kg})$ group 11 , few cells appear pale, Nissl material disappear, most of them appear normal. (Toluidine blue stain X500).

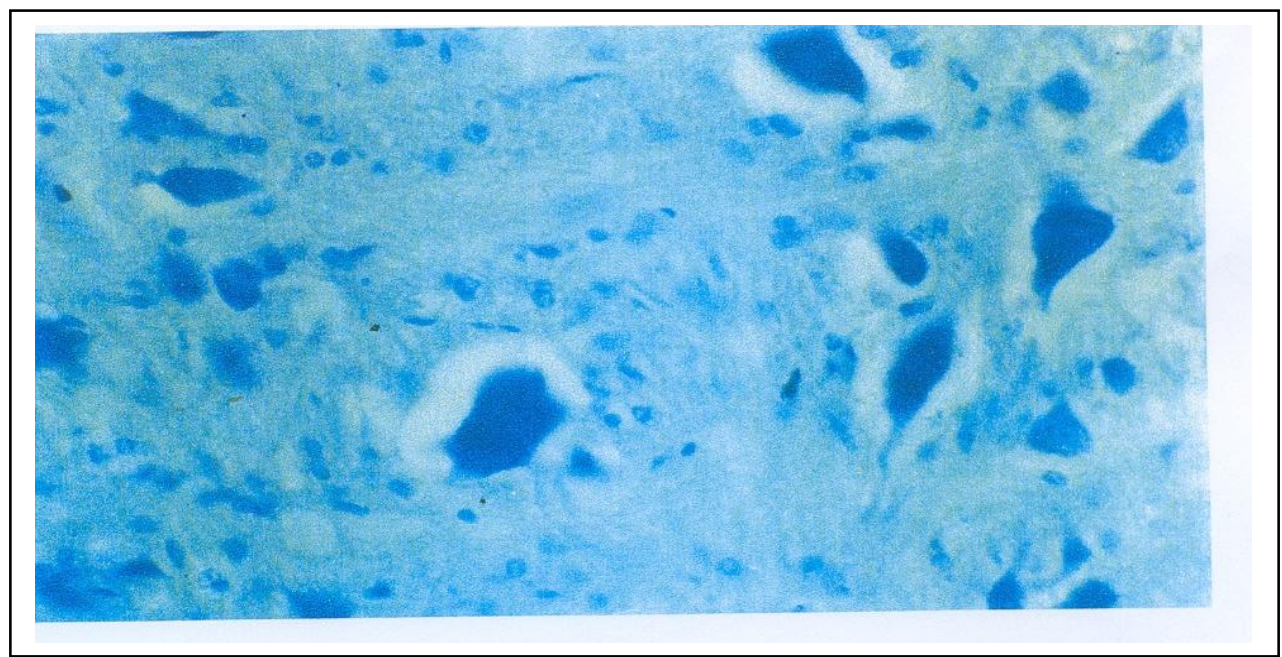

Fig (6) : Photomicrograph of section in rat's spinal cord showing the posterior horn cell after intrathecal injection with large dose of sufentanil $(7.5 \mu \mathrm{g} / \mathrm{kg})$ group 111, most of nerve cells are pale and chromatolytic, little of them appear normal. (Toluidine blue stain X500). 


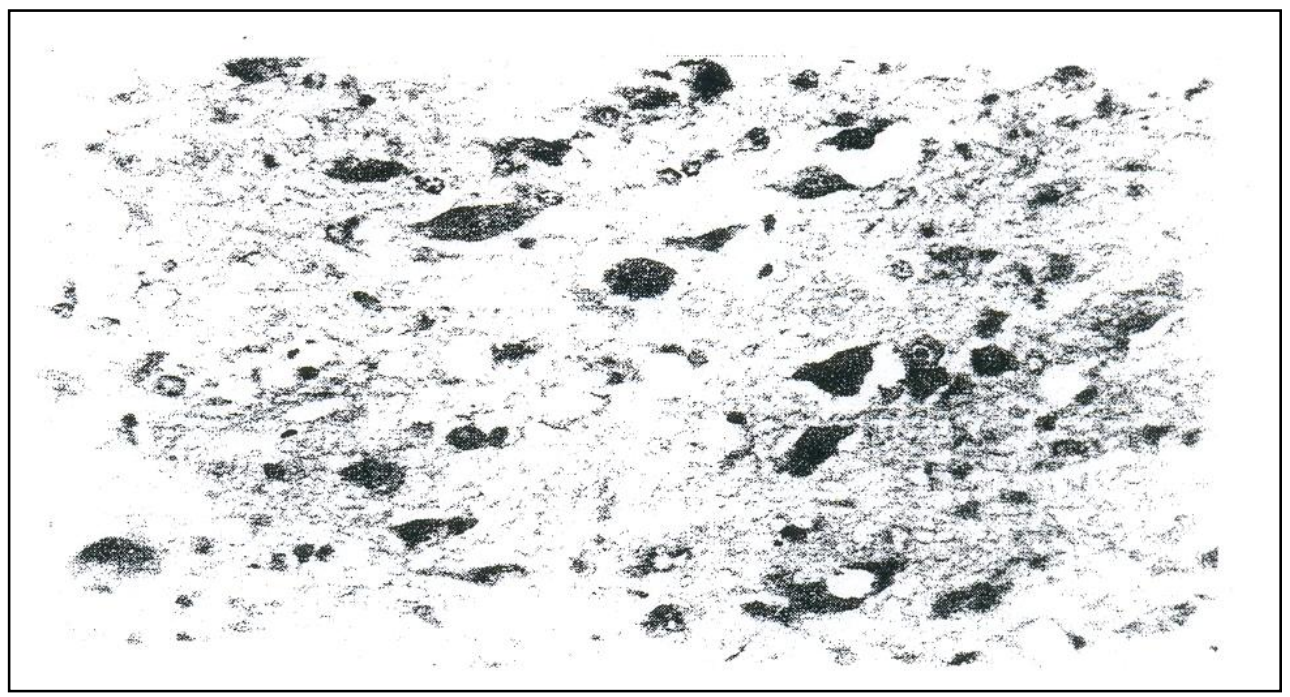

Fig (7) : Photomicrograph of section in rat's spinal cord showing the posterior horn cell of the control group showing the normal content of both RNA\&DNA (Methyl green pyronin X500).

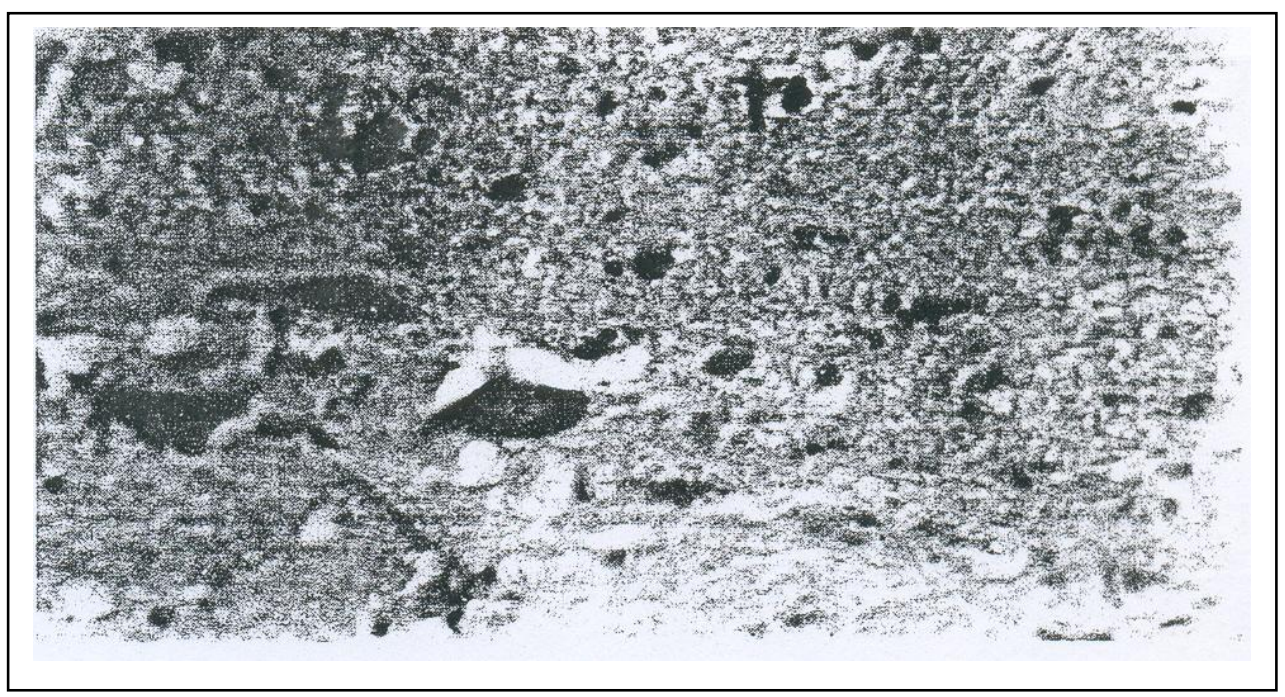

Fig (8) : Photomicrograph of section in rat's spinal cord showing the posterior horn cell after repeated intrathecal injection with low dose of sufentanil $(1.5 \mu \mathrm{g} / \mathrm{kg})$ group 11, showing no change in the nucleic acid content. (Methyl green pyronin X500). 


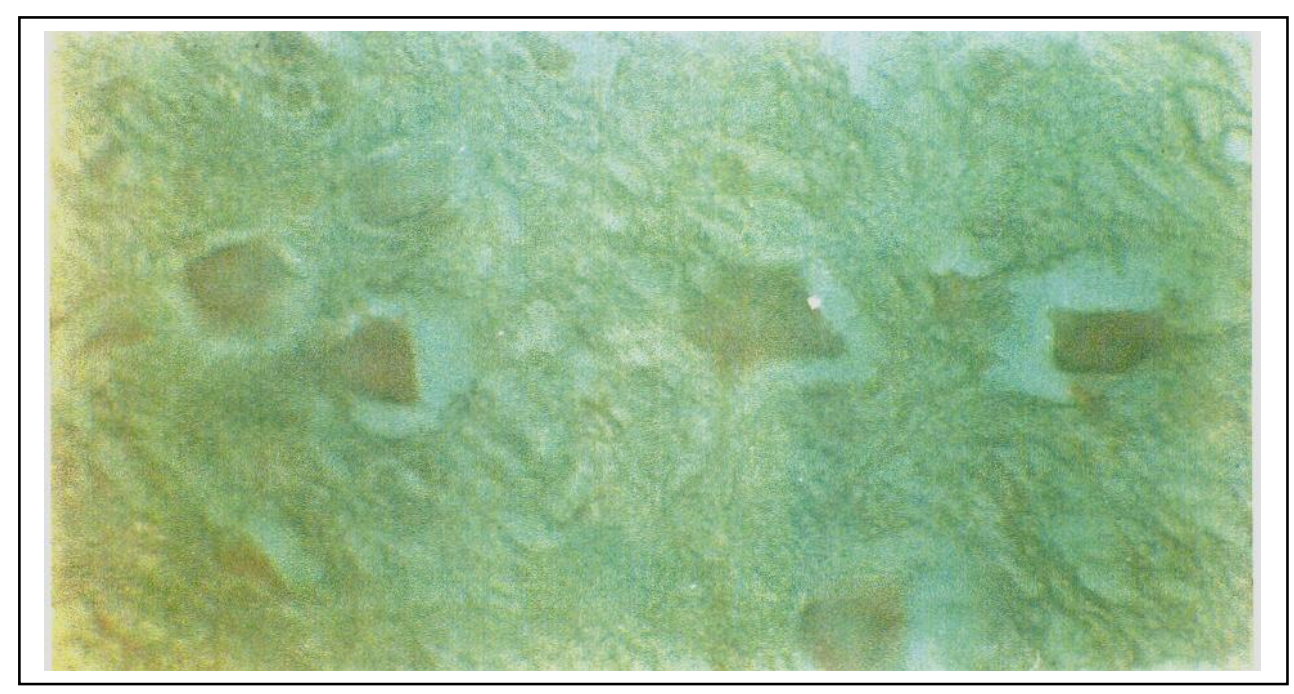

Fig (9) : Photomicrograph of section in rat's spinal cord showing the posterior horn cell after intrathecal injection with large dose of sufentanil $(7.5 \mu \mathrm{g} / \mathrm{kg})$ group 1I1, showing no change in nucleic acid content. (Methyl green pyronin X500).

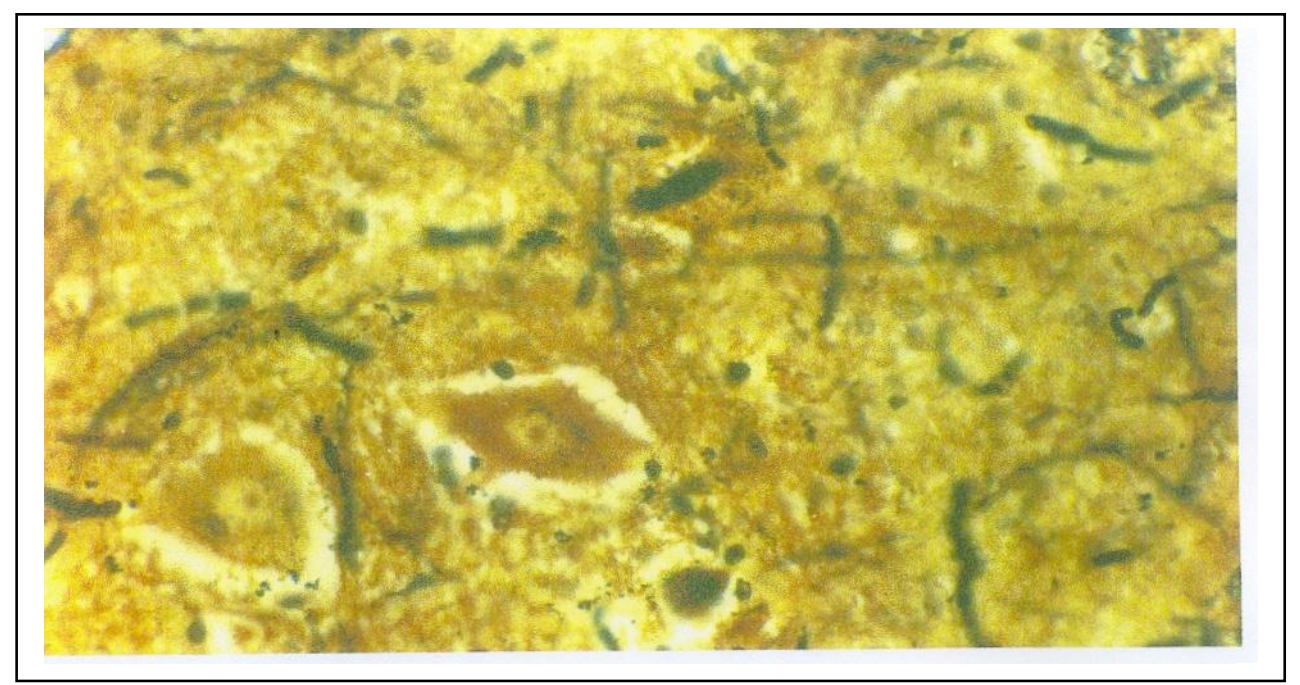

Fig (10) : Photomicrograph of section in rat's spinal cord showing the posterior horn cell of the control group showing no morphological changes (Nauta\&Gygax stain X500). 


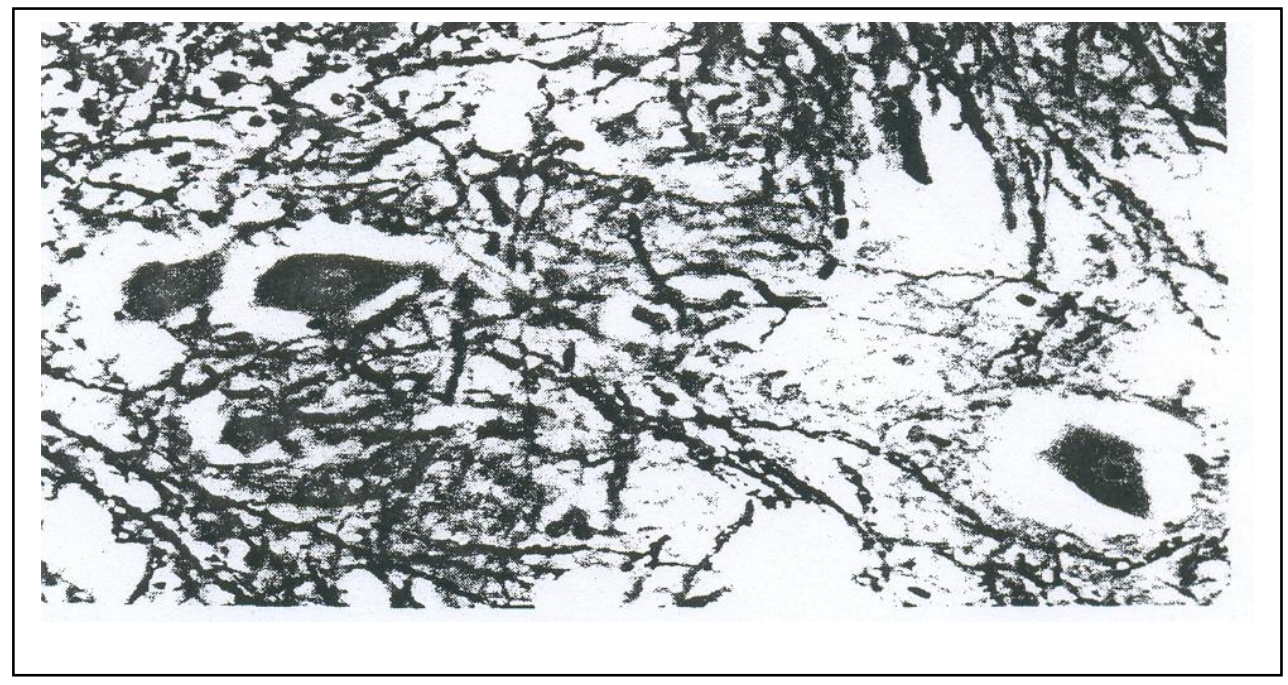

Fig (11) : Photomicrograph of section in rat's spinal cord showing the posterior horn cell after repeated intrathecal injection with low dose of sufentanil $(1.5 \mu \mathrm{g} / \mathrm{kg})$ group 11, few cellular shrinkage was noticed (Nauta\&Gygax stain X500).

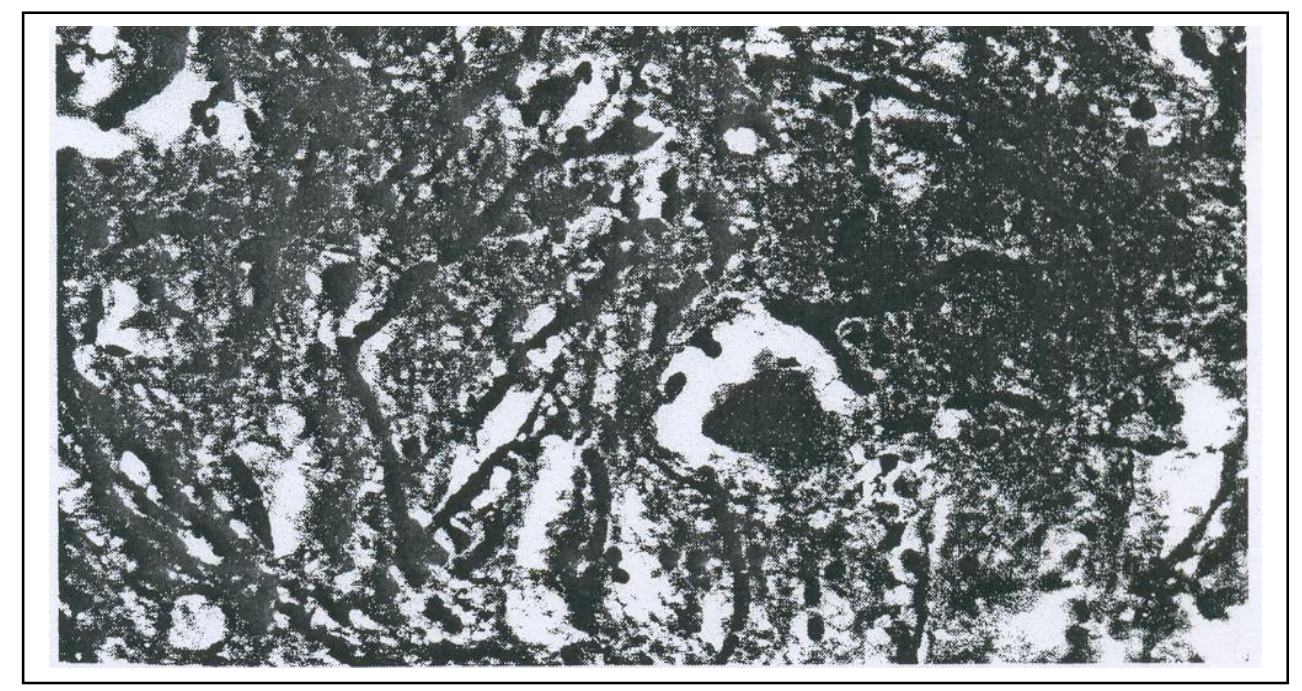

Fig (12) : Photomicrograph of section in rat's spinal cord showing the posterior horn cell after intrathecal injection with large dose of sufentanil $(7.5 \mu \mathrm{g} / \mathrm{kg})$ group 1I1, cellular shrinkage with irregularity in the thickness, varicosity and fragmentation of nerve fibers were noticed (Nauta\&Gygax stain X500). 


\section{Nagia M. Abd El Moeti et al}

\section{Discussion :}

Labour results in pain for most women. The ideal Labour analgesic technique should dramatically reduce the pain of labour, and have minimal effect on the fetus or the progress of Labour. (Birnbach, 2004). The possible methods of pain relief which can be used in Labour, neuraxial blockade (epidural, spinal, CSE) provides the most effective and least depressant analgesia. Epidural analgesia via catheter technique provides excellent pain relief and the ability to extend the duration of the block to match the duration of labour, but it is not instant in onset and may be associated with motor block. One-Shot spinal analgesia using a lipid soluble opioid is rapid and simple, but is associated with limited duration of action. The CSE provides the advantages of spinal (speed of onset, Lack of motor block) with the additional flexibility of renewal with an epidural catheter. (Eltzschig et al., 2003).

Our study was designed to compare the difference between CSE and epidural block using a narcotic (sufentanil) and local anaesthetic (bupivaicaine) regarding their effects on progress of labour, mode of delivery, pain relief, side effects also foetal and neonatal outcome.

Our study showed that CSE group had significant lower motor block than Epi group at 30min. Then the both groups showed no significant difference at 1 hour till the time of delivery. This result was in agreement with Norris et al. (2001) and Brenda et al. (2002).

As regard analgesic effects, the present study provides significally faster onset of analgesia (5.5min) with CSE as compared to the Epi group (20min.). However, half an hour after initiation of analgesia the VAPS was similar in both groups (VAPS $<3 \mathrm{~cm}$ ). These results are consistent with, Buckin et al. (2002). Also the CSE group had more patient satisfaction and less local anaesthetic consumption. Brenda et al, (2002).

Although regional analgesia provide excellent Labour pain relief it may affects the progress and outcome of Labour.
Conventional epidural analgesia has been reported to increase the duration of $1^{\text {st }} / 2^{\text {nd }}$ stage of Labour. Decreased uterine activity, longer Labour, loss of pelvic muscle tone and decreased ability to push in $2^{\text {nd }}$ stage. D'Angelo et al., (1994).

In this study there was faster initial cervical dilation and shorter time from starting of analgesia till full cervical dilation in CSE group. This in agreement with Tsen et al. (1999), and lawrence et al., (2002), who reported faster initial cervical dilation and shorter time from induction of analgesia till full cervical dilation amoung nulliparous receiving CSE analgesia versus epidural analgesia, however $2^{\text {nd }}$ stage duration and mode of delivery did not differ.

Potent opioids such as fentanyl and sufentanil are mainly used by either intrathecal or epidural route, Most studies refer to the use of combined spinal epidural technique with the injection of intrathecal sufentanil which results in quick and almost complete pain relief (within 5-10min) Riely et al., (1997). The efficacy, optimal dose, duration of analgesia and adverse side effects of epidural opioids have been extensively documented. Similar information is available for intrathecal opioids, the intrathecal route is a direct one because the drug is deposited close to its site of action. Plamer et al. (1999). The sufentanil dose chosen 10ug intrathecal has been used and validated in many clinical studies Nelson et al. (2002) and Debon et al. (2004). This dose represents the clinical dosage closest to the ED95 defined by Herman et al. (1997).

Although it provides excellent Labour pain relif, regional analgesia may affect the progress and outcome of Labour.

In the present study, there was no significant difference between the 2 groups in either the duration of the $2^{\text {nd }}$ Labour stage, mode of delivery (vaginal, instrumental, or caesarean section). These results are similar to the results of Nageotte et al. (1997). Also Gambling et al. (1998) and sharma et al. (2002) showed that both 
epidural and CSE analgesia does not increase the caesarean deliveries in nulliparous women compared with I.V meperidine analgesia.

Most studies suggest that incidence of abnormal FHR patterns is similar with either intrathecal or epidural Labour analgesia Eberle et al. (1998). However, Gambling et al. (1998), reported more caesarean deliveries for foetal indications among women receiving inrathecal sufentanil compared with those receiving I.V. meperidine. In contrast, Albright and Forster, (1997). Found no increase of emergency caesarean delivery for foetal indication among women receiving intrathecal sufentanil compared with those receiving either no or I.V Labour analgesia.

The present study confirm that the using of spinal or epidural sufentanil had not increased the rate of emergency C.S as a result of FHR abnormalities. This is similar to the result of Vane de Velde., (2001). However Segal et al. (1999) concluded that changes in FHR using intrathecal opioid may be due to an increase in uterine tone (uterine hyperactivity. Although Van de Velde et al. (2004) suggest a role of uterine hyperactivity without inducing more FHR abnormalities.

The results of our study showed that the neonatal Apgar scores and blood gas values to be similar between CSE and Epi groups and no worse neonatal outcome. This is in accordance with Gambling et al. (1998) and Eltzschig et al. (2003).

As regard to maternal haemodynamic effects. The present study showed a slight non significant decrease in MAP or HR compared to baseline values, also there was no significant difference between the 2 groups in HR and MAP. This is similar to Grant et al. (1996) and Riley et al. (1997). Several investigators have reported an association between epidural analgesia and either subclinical marternal hyperthermia or overt maternal fever Liberman et al. (1997). Thermo-regulatory changes with epidural analgesia may exert a hyper thermic effect. Sharma et al. (1997).

In our study there was no difference between CSE and epidural groups as regard to fever $(15 \%)$. This is coincide with Philip et al. (1999) and Sharma, (2000) who demonstrate that epidural analgesia during Labour is often associated with maternal fever to over $38^{\circ} \mathrm{C}$ in $15 \%$ of patients.

Also, our results showed no increase in neonatal sepsis with both groups. This is similar to Philip et al. (1999) who found no association between epidural analgesia and neonatal sepsis in febrile or afebrile women.

Other studies have demonstrated that infants of women who receive epidural analgesia are more likely to be evaluated and treated with antibiotics because of concern about infection. Liberman, (2000) and Althaus and wax, (2005).

A potential side effect of sufentanil like neuroaxial opioids is pruritus. In this study the incidence of pruritus was significantly higher with CSE group (40\%) versus epidural group (15\%). This is in agreement with study of Connelly et al. (2000), who proved that the incidence of pruritus was significantly higer with intrathecal opioids more than epidural ones.

Respiratory depression associated with spinal injection of opioides occurs with an incidence of $(0.01 \%-0.1 \%)$. Eisenoch, (1999).

In our study no cases of respirtory depression was observed. This is coincides with the study of Ching Cheag et al. (2001) who observed no clinically demonstrable respiratory compromise with intrathecal sufentanil.

As regards the risk of postdural puncture headache some investigators have expressed concern that the needle through needle technique may increase the frequency of subarachnoid catheter placement Narinder Rawal, (1999).

However neither our study nor studies by Vane Velde et al. (2001) could find any increase in risk of positional headache associated with the needle through needle CSE technique and epidural analgesia.

As regard neurological complications. Epidural and spinal anaesthesia are commonely associated with parathesia, but permanent trauma to spinal cord or nerve roots is rare. Moen et al. (2004).

In this study only one woman in CSE group complained of parathesia and burning 
pain in the lower part of thigh. The incidence of neurological injury in the United States after regional anaesthesia is low approximately 1 in 10.000 . Reynolds, (2001).

In this study $10 \%$ and $15 \%$ of CSE group and Epi group patients respectively reported mild sedation and did not require intervention this is coincide with Cohen et al. (1993).

The present study evaluated the histological changes following intrathecal injection of small $(1.5 \mathrm{ug} / \mathrm{kg})$ and large $(7.5 \mathrm{ug} / \mathrm{kg})$ doses of sufentanil in rat. The histological study revealed that there was no detectable statistical significant neurotoxic changes with the use of small dose of intrathecal sufentanil, but mild toxic effects in the form of some quantitative and chromatolytic changes in spinal cord cells were proved with large dose. This is similar to the results of Sabbe et al. (1994) and vercauteren and Meert, (1997).

Studies of the neurotoxicity of intrathecal sufentanil are controversial but Rawal et al. (1991) suggest a direct effect can not be excluded. Yaksh et al. (1986), found no abnormal histologic effects after acute or chronic administration in cats. Sabbe et al. (1994) reported no neuroto-

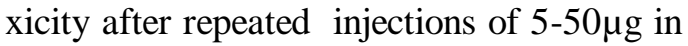
dogs .Small doses have induced only very mild histological damage in sheep and none in dogs or cats. large doses of sufentanil are rare but clinically relevant because they can be accidentally injected intrathecal or pass unintentionally by intrathecal route when administered epidurally (Malinovsky et al., 1996).

This study concludes that CSE provides faster onset of effective pain relif, increase the incidence of maternal satisfaction and less motor blockade. Itching is a more common complication after CSE analgesia. There is no difference between CSE and epidural techniques with respect to, the duration of $2^{\text {nd }}$ stage of Labour, mode of delivery, instrumental, Caesarean section rates and neonatal outcome. Also the incidence of other minor adverse effects is similar in both techniques.

\section{References}

1. Albright GA. Forster RM. (1997): Does combined spinal epidural analgesia with intrathecal sufentanil increase the incidence of emergency caeseran section. Reg. anesth., 22:400-405.

2. Althaus J and Wax J. (2005): Analgesia and anaesthesia in Labour. Obstetrics and Gynecology clinics., 32:2-5.

3. Bancroft JD, Stevens A and Pears AG (1957): Histological techniques $2^{\text {nd }}$ ed. Butter woths, London and Boston.

4. Birnbach DJ. (2004) : Adances in Labour analgesia. Canadian J.Anaesth.., 51:12:16.

5. Brenda A, David H, Joly L (2002): Intrathecal opioids versus epidural local anaesthetics for Labour analgesia: A meta analysis. Reg. Anesth. Pain med., 27(1-14).

6. Bucklin BA, Chestnut DH, Hawkins JL. (2002): Intrathecal opioids versus epidural local anaesthetic for Labour analgesia: A meta analysis (abstract). Anesthesiology; 93: A1043.

7. Chestnut D H. (1997) : Epidural analgesia and the incidence of Caesaren section; Time for another close look. Anaesthesiology., 87:472-6.

8. Ching cheag CJ, Sia TH, Lim EHL, et al. (2001): Either sufentanil or fenanil in addition to intrathecal bupivacaine provide satisfactory early Labour analgesia. Can. J. anesth., 48:570-74.

9. Cohen SE, Cherry CM, Holbrook RH Jr et al. (1993): Intrathecal sufentanil for Labour analgesia - sensory changes, side effects and foetal heart rate changes. Anesth. Analg., 77:1155-60.

10. Connelly N, Parker R, Vallurupulliv, et al. (2000): Comparison of epidural fentanil versus epidural sufentanil for analgesia in ambulatory patients in early Labour. Anesth. Anag., 91:374:78.

11. D' Angelo R, Anderson MT, Philip J et al. (1994): Intrathecal sufentanil compared to epidural bupivacaine for Labour analgesia. Anesthesiology., 80:1209-15.

12. Debon R, Boselli E, Guyot $\mathbf{R}$, et al. (2004): chrono pharmacology of intrathecal sufentanil for Labour analgesia. Anesthesiology., 101:240-44.

13. Eberle RL, Norris MC, Mallozzi EA et al. (1998): the effect of maternal position on foetal heart rate during eqidural or intrathecal Labour analgesia. Am. J. obestet. Gynecol.,179:150:55. 
14. Eltzschig HK, Lieberman ES and Camann WR. (2003): Regional anaesthesia and analgesia for Labour and delivery. N. Engl. J. Med., 348:319:322.

15. Gambling Dr, Sharma SK, Ramin SM et al. (1998): A randomized study of combined spinal - epidural analgesia versus intravenous meperidine during Labour: impact on caeseran delivery rate. Anesthesiology., 89:1336-44.

16. Grant GJ, Susser L., Cascio M et al. (1996): Haemodynamic effects of intrathecal fentanil in non labouring term parturients. J. clin. Anesth., 8:99-103.

17. Herman NL, Calicott R, Van Decar TK et al. (1997): Determination of the doseresponse relationship for intrathecal sufentanil in Labouring patients. Anesth. Analg., 84:1256-61.

18. Lawrence C. Tsen MD, Scott Segal MD (2002): Combined spinal - epidural versus epidural Labour analgesia on progress of Labour. Anesthesiology., 97:1-3.

19. Liberman E, Eichenwald E, Mathur G et al. (2000): Intrapartum fever and unexplained seizures in term infant. Paediatrics., 106:983-88.

20. Liberman E, Lang JM, Frigoletto F Jr, et al. (1997): Epidural analgesia, intrapartum fever and neonatal sepsis evaluation. Paediatrics., 99:415-19.

21. Malinovsky JM, Lepage JY, Cozian A et al. (1996): Transient Muscular spasm after a large dose of intrathecal sufentanil. Anesthesiology ., 84:1513-15.

22. Moen V, Dahlgren N, Irestedt L,(2004): Severe neurological complications after central neuraxial blockades in Sweden 1990-1999. anesthesiology., 101:950-59.

23. Nageotte MP, Larson D, Rumney PH, et al. (1997): epidural analgesia compared with combined spinal epidural analgesia during Labour in nulliparous women. N. Eng. J. Med., 337:1715-19.

24. Narinder Rawal (1999): Pain control in the perioperative period. Surgical clinics of north America., 79:313-40.

25. Nauta WIH and Gygax PA (1951) : Silver impregnation of the degenerating axons terminals in the central nervous system. Stain tech., 26:5-11.

26. Nelson KE, Rauch T, Terebuh V etal. (2002): A comparison of intrathecal fentail and sufentanil for Labour analgesia. Anesthesiology., 96:1070-73.

27. Norris MC, Fogel ST, and Conway Long C. (2001): Combined spinal epidural versus epidural Labour analgesia. Anesthesiology; 95:913-20.

28. Norris MC, Grieco WM, Borkwski M,Leighton BI et al. (1994) Complications of Labour analgesia : Epidural versus combined spinal epidural techniques. Anesth. Analg., 79:529-37.

29. Philip J, Alexander JM, Sharma SK. et al. (1999): Epidural analgesia during Labour and maternal fever. Anesthesiology; 90:1271-75.

30. Plamer CM, Maciulla JE, Cork RC, Nogami WM, et al. (1999): the incidence of foetal heart rate changes after intrathecal fentanyl Labour analgesia. Anesth. Analg., 88:577-81.

31. Ralis HM, Beesley RA and Ralis ZN (1973): Techniques in neurohistology, $1^{\text {st }}$.ed. p.84-88. London, sydny, Toronto, Wellington and Duraban.

32. Rawal N, Nuutinen Ls, Raj pp, Lovering SL, et al. (1991) : Behavioral and histopathologic effects following intrathecal administration of butorphenol, sufentanil and nalbuphine in sheep. Anesthesiology ., 75:1025-34

33. Riely ET, Ranter EF, and Cohen SE. (1997): Intrathecal sufentanil for Labour analgesia: do sensory changes predict better analgesia and greater hypotension? Anesth. Analg.;84:346-51.

34. Reynolds F (2001): Damage to the conus medullaris Following spinal anaesthesia. Anaesthesia; 56:238-47.

35. Sabbe MB, Grafe MR, Mjanger E et al. (1994): Spinal delivery of sufentanil, Alfentanil and Morphine in Dogs. Physiologic and toxicologic investigations. Anesthesiology; 81:899-920.

36. Segal S, Blatman R, Doble M, and Datta S. (1999): the influence of the obstetrician in the relationship between epidural analgesia and caesarean section for dystocia. Anesthesiology; 91:90-96.

37. Sharma SK. (2000): Epidural analgesia during Labour and maternal fever. Current opinion in Anesthesiology.,13 : 257-60.

38. Sharma SK, Alexander JM, Messick G et al. (2002): caesarean delivery: a randomized trial of epidural analgesia versus intravenous meperidine analgesia during labout in nulliparous women. Anesthesiology., 96:546-51.

39. Sharma Sk, Sidawi J.E, Ramin. SM, Lucas Mj, et al. (1997): Caesarean delivery : A randomized Trial of epidural versus patient - controlled meperidine 
analgesia during Labour. Anesthesiology., 87:487-94.

40. Tsen LC, Thue B, Datta Sand Segal S(1999): Is combined spinal epidural analgesia associated with more rapid cervical dilation in nulliparous patient when compared with convential epidural analgesia. Anesthesiology., 91:920-25.

41. Van de Velde M. (2004): Intrathecal sufentanil and foetal heart rate abnormalities: a double-blind double placebo controlled trial comparing two forms of combined spinal epidural analgesia with epidural analgesia in labour. Anesth. Analg., 98:1153-59.
42. Van de Velde $M$, Vercauteren $M$, Vandermeersch E.(2001): Foetal heart rate abnormalities after regional analgesia for Labour pain: the effect of intrathecal opioids. Reg. anasth. Pain Med., 26:257-62.

43. Vercauteren M, Meert TF. (1997): Isobolographic analysis of the interaction between epidural sufentanil and bupivacaine in rats. Pharmacol. Biochem. Behav., 58:237-42.

44. Yaksh TL, Noueihed RY, Durant PAC. (1986) : Studies of pharmacology and pathology of intra-thecally admininistered 4 anilinopiperidine analogues and morphine in the rat and cat. Anesthesiology., 64:5466. 


\section{حقن المسكنات خارج وداخل الام الجافية مقارنة بالحقن خارج الام الجافية

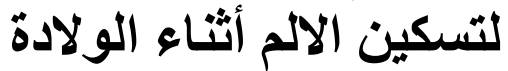

نجية محمد عبد المعطى * ، زينب بيومى يوسف * ، سعاد سيد عبد العال * ،

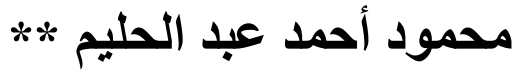

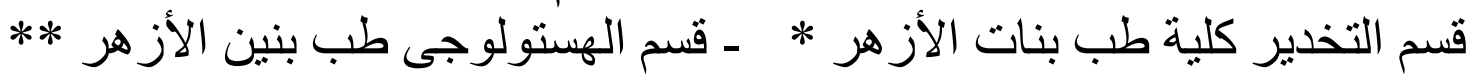

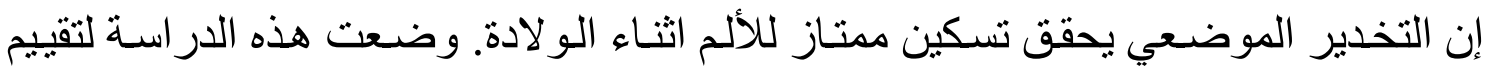

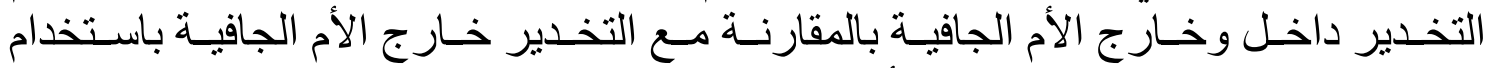

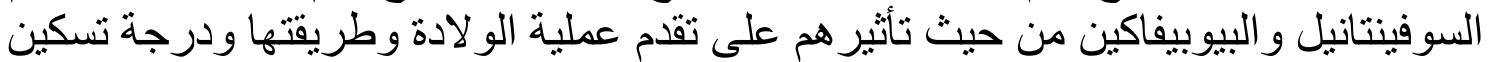

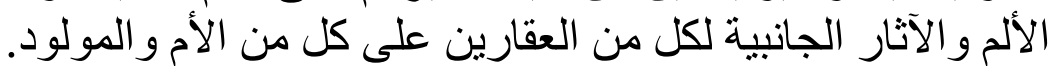

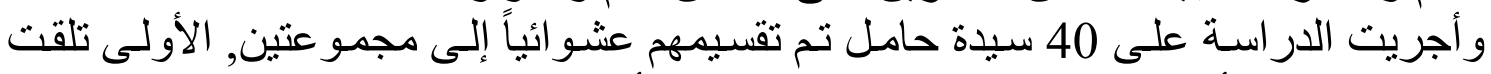

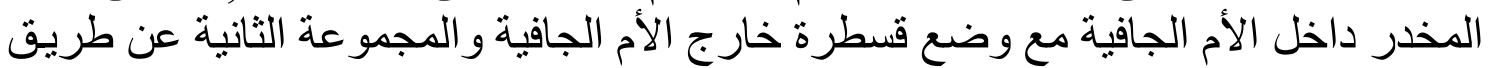

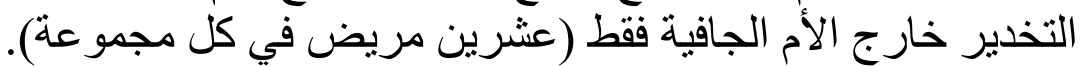

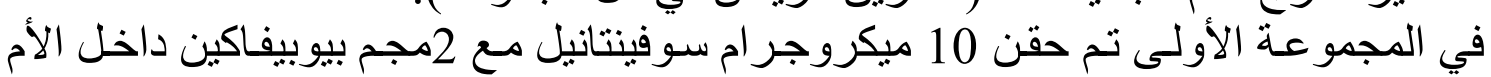

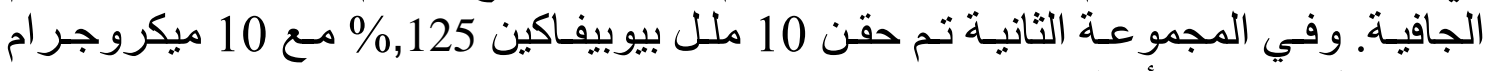
سوفينتانيل. خارج وفي الأم الجافية

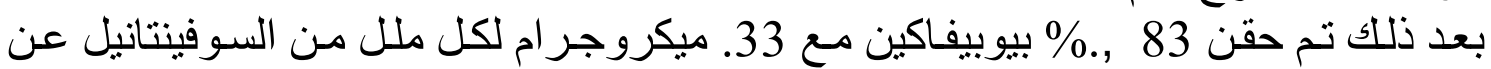

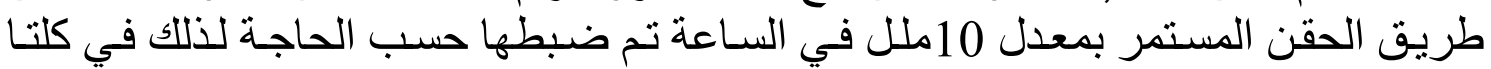

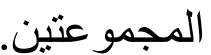

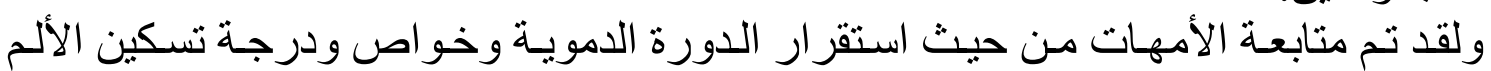

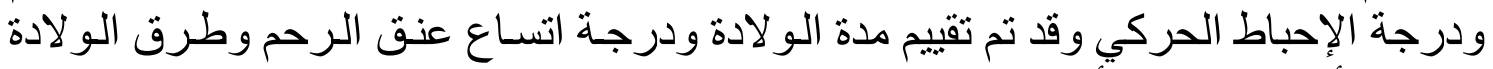

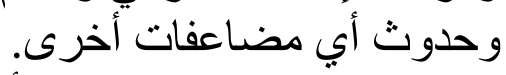

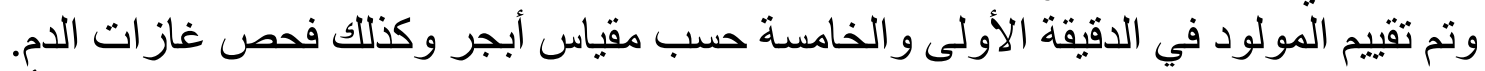

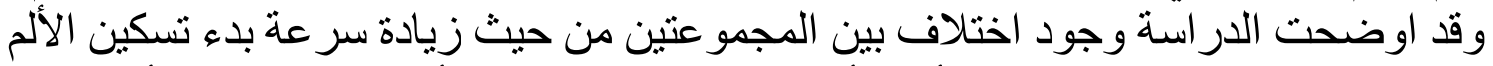

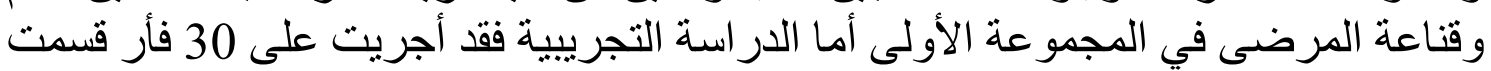

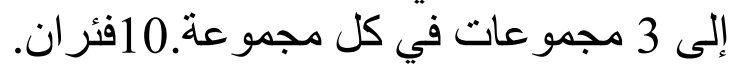

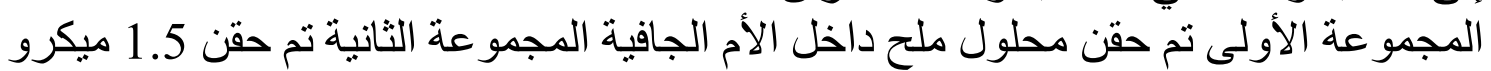

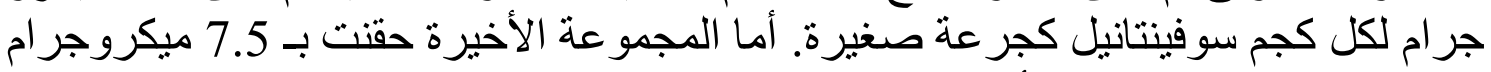

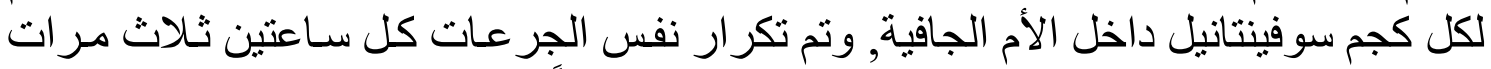

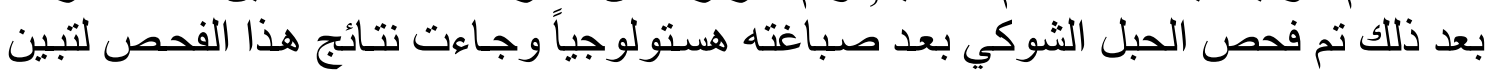

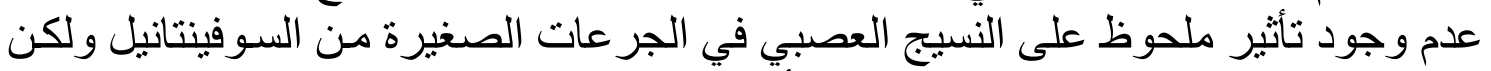

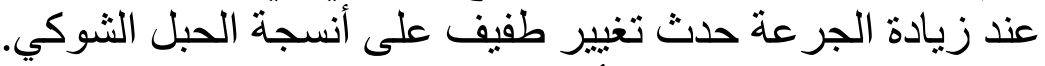

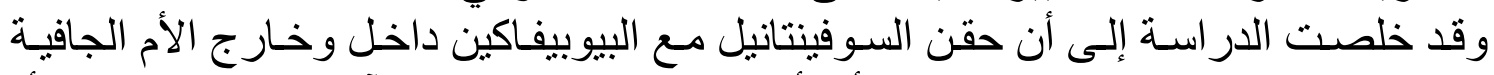

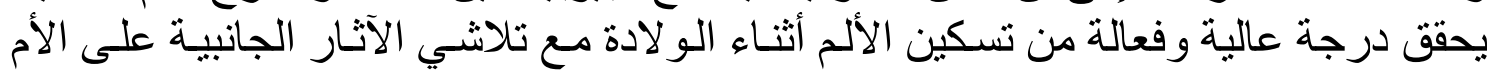

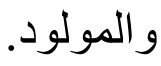

